\title{
Physical Training Status Determines Oxidative Stress and Redox Changes in Response to an Acute Aerobic Exercise
}

\author{
Farnaz Seifi-skishahr, ${ }^{1,2}$ Arsalan Damirchi, ${ }^{1}$ \\ Manoochehr Farjaminezhad, ${ }^{3}$ and Parvin Babaei ${ }^{4,5}$ \\ ${ }^{1}$ Department of Sport Physiology, Faculty of Physical Education and Sport Sciences, University of Guilan, Rasht, Iran \\ ${ }^{2}$ Department of Physical Education and Sport Sciences, Faculty of Education and Psychology, \\ Mohaghegh Ardabili University, Ardabil, Iran \\ ${ }^{3}$ Medicinal Plants Research Center, Ardabil Branch, Islamic Azad University, Ardabil, Iran \\ ${ }^{4}$ Department of Physiology, Faculty of Medicine, Guilan University of Medical Sciences, Rasht, Iran \\ ${ }^{5}$ Cellular \& Molecular Research Center, Guilan University of Medical Sciences, Rasht, Iran \\ Correspondence should be addressed to Parvin Babaei; p_babaei@gums.ac.ir
}

Received 19 October 2015; Revised 19 January 2016; Accepted 11 February 2016

Academic Editor: Saad Tayyab

Copyright (C) 2016 Farnaz Seifi-skishahr et al. This is an open access article distributed under the Creative Commons Attribution License, which permits unrestricted use, distribution, and reproduction in any medium, provided the original work is properly cited.

\begin{abstract}
Objective. To assess the influence of different physical training status on exercise-induced oxidative stress and changes in cellular redox state. Methods. Thirty male subjects participated in this study and were assigned as well-trained (WT), moderately trained (MT), and untrained (UT) groups. The levels of cortisol, creatine kinase, plasma reduced glutathione to oxidized glutathione (GSH/GSSG), cysteine/cystine (Cys/CySS), and GSH/GSSG ratio in red blood cells (RBCs) were measured immediately and 10 and $30 \mathrm{~min}$ after exercise. Results. Following the exercise, plasma GSH/GSSG $(p=0.001)$ and Cys/CySS $(p=0.005)$ were significantly reduced in all groups. Reduction in plasma GSH/GSSG ratio in all groups induced a transient shift in redox balance towards a more oxidizing environment without difference between groups ( $p=0.860$ ), while RBCs GSH/GSSG showed significant reduction $(p=0.003)$ and elevation $(p=0.007)$ in UT and MT groups, respectively. The highest level of RBCs GSH/GSSG ratio was recorded in MT group, and the lowest one was recorded in the WT group. Conclusion. Long term regular exercise training with moderate intensity shifts redox balance towards more reducing environment, versus intensive exercise training leads to more oxidizing environment and consequently development of related diseases.
\end{abstract}

\section{Introduction}

The redox state represents the oxidation/reduction potential within the cell and plays an important role in cells function [1]. The three most important redox systems are nicotinamide adenine dinucleotide phosphate (NADPH/NADP+), thioredoxin (reduced/oxidized TRX), and glutathione (reduced/ oxidized glutathione). Glutathione is one of the most important antioxidants, protecting tissues from oxidative damage [2], and helps to maintain homeostasis [3] and redox status [4]. Generally, in all redox systems, the relative amounts of reduced (more negative) and oxidized (more positive) form determine cellular redox state [2] and more reduced redox represents healthy status [5], while more oxidized form predisposes individuals to aging and diseases $[6,7]$. Therefore, the ratio of GSH and GSSG is in the core of the redox hypothesis $[8,9]$ and directly reflects intracellular redox alterations at resting and provocative states [10].

It has been known that exercise of sufficient volume, intensity, and duration can induce oxidative stress [11] and leads to disturbing cellular metabolism and function [12, 13]. In other words, the conditions that favor accelerated production of free radicals cause a permanent shift in redox balance towards a more oxidized environment [6] and lead to disturbing proteins and lipids [14]. On the other hand, the low-molecular-weight thiol/disulfides, such as GSH/ GSSG and Cys/CySS, exist under nonequilibrium states in which the kinetics of oxidation and reduction determine 
TABLE 1: Subjects' characteristics of WT, MT, and UT groups.

\begin{tabular}{|c|c|c|c|c|c|}
\hline Characteristics & WT group & MT group & UT group & $F$ & $p$ value \\
\hline Age (yr) & $21.10 \pm 1.72$ & $21.70 \pm 1.88$ & $20.10 \pm 1.44$ & 2.264 & 0.123 \\
\hline Weight $(\mathrm{kg})$ & $69.00 \pm 6.94$ & $69.40 \pm 9.81$ & $73.20 \pm 9.47$ & 0.688 & 0.511 \\
\hline Height $(\mathrm{cm})$ & $176.00 \pm 7.87$ & $173.20 \pm 5.78$ & $176.90 \pm 4.28$ & 0.981 & 0.388 \\
\hline BMI $\left(\mathrm{kg} / \mathrm{m}^{2}\right)$ & $22.28 \pm 1.87$ & $23.12 \pm 3.01$ & $23.37 \pm 2.74$ & 0.485 & 0.621 \\
\hline $\mathrm{Vo}_{2} \max (\mathrm{mL} / \mathrm{kg} / \mathrm{min})$ & $60.90 \pm 3.96$ & $52.76 \pm 2.62$ & $43.63 \pm 4.11$ & 56.538 & $<0.001^{*}$ \\
\hline Body fat $\%$ & $9.15 \pm 0.96$ & $11.68 \pm 1.74$ & $15.98 \pm 4.17$ & 16.669 & $<0.001^{*}$ \\
\hline Years of training (yrs) & $\approx 10.00$ & $\approx 10.00$ & 0 & - & - \\
\hline Training $\left(\mathrm{h} \cdot\right.$ week $\left.^{-1}\right)$ & $6.4 \pm .33$ & $1.20 \pm 0.16$ & 0 & - & - \\
\hline
\end{tabular}

Data are mean \pm SD. *A significant between-groups difference tested by ANOVA with Tukey post hoc test.

the steady-state balance of reduced and oxidized forms [15]. This displacement from equilibrium allows rapid and dynamic regulation, supports redox signaling, and represents a central target of nonradical mechanisms of oxidative stress [8]. Therefore, GSH/GSSG and Cys/CySS couples in blood plasma represent a clinical measure of oxidative stress [4].

Here, it is assumed that individual's state of training could be important to determine the extent of redox homeostasis following acute bout of exercise [16-18], more notably the level of GSH [19]. Our hypothesis was that individuals with different history of physical activity should have different redox state and react in a different way encountering acute stress. To our knowledge, the changes in GSH redox status during exercise have been investigated in two human studies $[16,20]$. Thus, the present study was designed to compare GSH redox status of individuals with three distinct exercise training statuses at rest and also in response to acute exercise.

\section{Materials and Methods}

2.1. Subjects. Thirty voluntary well-trained ( $n=10$, WT group), moderately trained ( $n=10$, MT group), and untrained ( $n=10$, UT group) male subjects participated in this study. Subjects from WT group were selected from elite soccer players who played in teams of the highest division of league in Ardebil. Based on self-reported frequency of physical training, the other groups were identified: moderately trained subjects with regular physical training (walking, jogging, bicycling, basketball, and soccer). Untrained subjects had no physical training or sport in their routine (more detailed information about subjects is seen in Table 1).

At the beginning of the experiment, the study protocol was approved by the Ethical Committee of Ardebil University, and then participants completed medical history questionnaire and signed informed consent. None of the participants showed signs of bacterial or viral infection symptoms. In addition, other exclusion criteria were drinking alcohol, smoking, and taking anti-inflammatory drugs or antioxidant supplements.

2.2. Procedures. Generally, this study was designed in two parts: the preliminary and main exercise trials.

2.2.1. The Preliminary Trial. Two weeks prior to enrollment into the study, all subjects passed a physical examination and a maximal oxygen consumption $\left(\mathrm{Vo}_{2} \max \right)$ test.
2.2.2. Subjects Characteristics. The subjects' weight and height were recorded using electronic scale (model 712; Seca, Germany) and portable Stadiometer (Holtain, UK), respectively, and then participants completed a body composition assessment.

2.2.3. Maximal Oxygen Consumption ( $\mathrm{Vo}_{2}$ max). All subjects performed an incremental test on a treadmill (Model 6150E, Sport Art, UK) using Bruce test [21] 1-2 h after breakfast.

2.2.4. Dietary Assessment. All subjects kept their normal diet during the study period and completed daily food records until the day of experiment. Diet records were analyzed for total kilocalories, protein, carbohydrate, fat, vitamin C, vitamin $\mathrm{E}$, vitamin $\mathrm{A}$, antioxidants sources, and selenium intake using commercial software (Food Processor IV; Nutrition System, Iran).

2.2.5. Exercise Protocol. Subjects completed exercise protocol including $5 \mathrm{~min}$ running with $50 \% \mathrm{Vo}_{2} \mathrm{max}$ and $30 \mathrm{~min}$ running with $75 \% \mathrm{Vo}_{2} \max$ on treadmill, while heart rate was continuously monitored using short-range telemetry (Polar S610, Polar Electro, Finland). Water consumption was encouraged throughout the main trial. Blood samples were taken before the exercise (following overnight fasting) and immediately, $10 \mathrm{~min}$, and $30 \mathrm{~min}$ after the exercise protocol from an antecubital vein.

\subsection{Outcome Measures}

2.3.1. Sample Preparation. The blood samples were transferred to four aliquots: the first vials containing EDTA were left at room temperature for 2 hours, and then they were used for measuring hemoglobin and hematocrit using automated Coulter Counter (Sysmex k-x21) in order to correct plasma volume shifts [22]. The second vials were centrifuged at $1600 \mathrm{~g}$ for $5 \mathrm{~min}$ for cortisol and creatine kinase (CK) measurement in serum, and the last vials containing EDTA were immediately transferred on ice and then centrifuged at $1600 \mathrm{~g}$ for $5 \mathrm{~min}$. Erythrocytes were washed twice with cold $9 \% \mathrm{NaCl}$ solution and were lysed by freezing for 2 hours. Finally, hemolysate $(100 \mathrm{~mL})$ was deproteinized by adding $400 \mathrm{~mL}$ of $6 \% \mathrm{MPA}$ and $100 \mathrm{~mL}$ of glutathione ethyl ester as internal standard. Precipitated proteins were removed by centrifugation $\left(7 \mathrm{~min}, 10000 \mathrm{~g}\right.$, and $\left.48^{\circ} \mathrm{C}\right)$. The resulting supernatant was used for measurement of GSH and total GSH 
TABLE 2: Estimated percentage of changes in plasma volume in the groups of WT, MT, and UT.

\begin{tabular}{lcccccc}
\hline Parameter & Pre-exs & Post-exs & Post-10 min & Post-30 min & $F$ & $p$ value \\
\hline Plasma volume change, WT group & - & $-0.71 \pm 1.80$ & $2.63 \pm 1.47$ & $2.78 \pm 1.55$ & 0.087 & 0.917 \\
MT group & - & $-0.78 \pm 0.53$ & $1.70 \pm 1.30$ & $1.41 \pm 1.47$ & 1.242 & 0.305 \\
UT group & - & $-0.49 \pm 1.22$ & $0.85 \pm 1.97$ & $-0.68 \pm 2.28$ & 0.939 & 0.403 \\
\hline
\end{tabular}

Data are mean \pm SEM. $p$ value calculated using ANOVA with Tukey post hoc test.

in RBCs [23]. The fourth vials $(1350 \mu \mathrm{L})$ were centrifuged and were stored at $-80^{\circ} \mathrm{C}$ until GSH/GSSG and Cys/CySS analysis. Another microtube labeled N containing $1350 \mu \mathrm{L}$ was centrifuged for $1 \mathrm{~min}$ in isolate RBC. Then, $200 \mu \mathrm{L}$ of supernatant was transported to a microcentrifuge tube labeled $\mathrm{S}$ and was stored at $-80^{\circ} \mathrm{C}$. This method of sample preparation and storage reduces probability of artifacts production during hemolysis or GSH thiol-disulfide exchange [5].

2.3.2. Measurement of Serum Creatine Kinase Activity and Cortisol. Serum cortisol level was measured using chemiluminescent immunoassay and a commercial kit (Liaison, USA). Creatine kinase activity was measured by spectrophotometry using a commercial kit (Pars Azmoon Lab, Iran).

\subsubsection{Measurement of the Thiol and Disulfide Forms of} Glutathione and Cysteine in Plasma and RBCs. Highperformance liquid chromatography (HPLC) with fluorescence detection was used for plasma (with minor modifications) [5] and RBCs markers [23]. The HPLC analyses were performed with Agilent 1200 series HPLC systems equipped with a quaternary pump system (G1311A) and a fluorescence detector (G1321A) (Agilent Technologies, Waldbronn, Germany) by using reversed phase gradient elution on Eclipse XDB-C18 column $(150,4.6 \mathrm{~mm} ; 5 \mu \mathrm{m}$ particle size). Briefly, samples in $S$ tubes were spun for 2 min in microcentrifuge to precipitate protein. A $300 \mu \mathrm{L}$ aliquot of each supernatant $(\mathrm{pH}=9.0 \pm 0.2)$ was mixed with $300 \mu \mathrm{L}$ of the dansyl chloride solution for derivatization and placed in the dark at room temperature for 24 hours. Chloroform $(500 \mu \mathrm{L})$ was added to each tube to extract the unreacted dansyl chloride. An aliquot of the upper layer $(20 \mu \mathrm{L})$ was injected to the system. The mobile phase was composed of solvent A containing methanol/water (80/100) and solvent $\mathrm{B}$ was an acetate-buffered $(\mathrm{pH}=4.6)$ methanol solution prepared by mixing $640 \mathrm{~mL}$ of methanol, $200 \mathrm{~mL}$ of acetate stock, $125 \mathrm{~mL}$ of glacial acetic acid, and $50 \mathrm{~mL}$ of water. The retention times of GSH, GSSG, Cys, and CySS were 19.1, 22.3, 10.1 , and $8.4 \mathrm{~min}$.

For any measurements in RBCs, first $100 \mu \mathrm{L}$ of precipitated proteins sample from hemolyzed erythrocytes was derivatized with $100 \mu \mathrm{L}$ of an ortho-phthalaldehyde solution and $800 \mu \mathrm{L}$ of $500 \mathrm{mM}$ sodium phosphate $(\mathrm{pH}=7.00)$. A mobile phase was composed of $50 \mathrm{mM}$ of sodium acetate buffer $(\mathrm{pH}=6.20)$ and acetonitrile. Fluorimetric detection was performed at $420 \mathrm{~nm}$ after excitation at $340 \mathrm{~nm}$. The flow rate during elution was $0.7 \mathrm{~mL} / \mathrm{min}$, the retention time of GSH was $3.6 \mathrm{~min}$, and the injection volume was $20 \mu \mathrm{L}$. GSSG concentration was obtained from subtraction of the
GSH from the total glutathione (GSHt) values assessed by this method performing a reduction step of GSSG with dithiothreitol before protein precipitation.

2.3.4. Analysis. The results are presented as mean \pm SEM, except for subject characteristics, which are presented as mean \pm SD. All data were analyzed for their normal distribution using KS test. Subject characteristics, dietary data, and estimated percentage of changes in plasma volume were analyzed by using ANOVA. A univariate GLM for repeated measures was used to analyze the differences within groups and for fixed between-groups factors, Bonferroni test was used for multiple comparison tests. Also, ANOVA with Tukey post hoc test was used to analyze the differences between and within groups. Calculations were performed with the SPSS, Version 20.0 (SSPS Inc., Chicago, IL), statistical package. Statistical significance was defined as $p<0.05$.

\section{Results}

The physiological characteristics of the participants are represented in Table 1. All subjects showed normal BMI with no significant differences between groups (WT group: $22.28 \pm 1.87$; MT group: $23.12 \pm 3.01$; UT group: $23.37 \pm$ $\left.2.74 \mathrm{~kg} / \mathrm{m}^{2}\right)$. The differences found in self-reported training questionnaire were confirmed by differences in aerobic fitness levels, as resulting from the maximal oxygen uptake $\left(\mathrm{Vo}_{2} \mathrm{max}\right)$ and body fat percentage. The well-trained group including 10 soccer players showed the highest training level $(6.4 \pm 0.33 \mathrm{~h} /$ week $)$, MT group included 10 subjects with the intermediate training frequency $(1.20 \pm 0.16 \mathrm{~h} /$ week $)$, and UT group included 10 subjects with the lowest $\mathrm{Vo}_{2} \max$ $(43.63 \pm 4.11 \mathrm{~mL} / \mathrm{min} / \mathrm{kg})$ and greatest body fat percentage $(15.98 \pm 4.17 \%)$, with no physical training history in the recent 10 years. Neither of the groups showed significant changes in plasma volume during the experiment (Table 2). Also, no significant difference was observed in the calculated amount or composition of the 3-day food consumption before the main trial (Table 3).

3.1. Stress Hormone Response. Table 4 shows the mean $( \pm$ SEM) values for serum cortisol concentration. It was increased significantly after exercise in the WT $(p=0.003)$, MT $(p=0.034)$, and UT $(p<0.001)$ groups compared to before exercise. There was no significant between-groups difference either in preexercise $(F=1.084, p=0.365)$ or in postexercise $(F=0.536, p=0.591)$ values.

3.2. Muscle Damage. Table 4 shows the mean $( \pm$ SEM $)$ values of serum CK activity. It was significantly increased 
TABLE 3: Dietary intake assessment during the 3-day period prior to the main trial.

\begin{tabular}{|c|c|c|c|c|c|}
\hline & WT group & MT group & UT group & $F$ & $p$ value \\
\hline Kilocalories & $2817.40 \pm 220.66$ & $2864.70 \pm 156.16$ & $2455.20 \pm 110.29$ & 1.766 & 0.190 \\
\hline Protein & $106.11 \pm 10.17$ & $106.27 \pm 6.35$ & $96.34 \pm 5.46$ & 0.558 & 0.579 \\
\hline Carbohydrate & $466.65 \pm 47.43$ & $421.49 \pm 33.24$ & $348.58 \pm 31.41$ & 2.452 & 0.105 \\
\hline Fat total & $59.49 \pm 3.44$ & $77.61 \pm 2.60$ & $70.75 \pm 8.50$ & 2.760 & 0.081 \\
\hline SFA & $18.79 \pm 2.45$ & $23.35 \pm 2.65$ & $17.19 \pm 2.99$ & 1.388 & 0.267 \\
\hline MUFA & $16.14 \pm 2.82$ & $24.72 \pm 2.20$ & $18.71 \pm 2.77$ & 2.829 & 0.077 \\
\hline PUFA & $14.26 \pm 2.27$ & $20.10 \pm 2.61$ & $21.12 \pm 4.10$ & 1.423 & 0.258 \\
\hline Vitamin C & $39.48 \pm 9.56$ & $42.54 \pm 10.61$ & $57.32 \pm 20.85$ & 0.427 & 0.657 \\
\hline Vitamin E & $15.91 \pm 2.96$ & $24.62 \pm 2.68$ & $18.82 \pm 2.53$ & 2.630 & 0.090 \\
\hline Vitamin A total & $251.41 \pm 34.32$ & $213.55 \pm 29.45$ & $153.48 \pm 30.66$ & 2.450 & 0.105 \\
\hline Carotene & $79.40 \pm 9.01$ & $74.30 \pm 9.16$ & $51.70 \pm 9.79$ & 2.496 & 0.101 \\
\hline Selenium & $0.05 \pm 0.01$ & $0.08 \pm 0.02$ & $0.06 \pm 0.01$ & 0.593 & 0.560 \\
\hline
\end{tabular}

Gram quantities for each macronutrient are provided. Vitamin $\mathrm{C}$ and vitamin $\mathrm{E}$ are provided in milligrams. Vitamin A values are provided in retinol equivalents. Data are mean \pm SEM. $p$ value calculated using ANOVA.

immediately after exercise in all groups $(p<0.001)$. The greatest but insignificant preexercise value was observed in WT group compared with MT and UT group $(F=0.309$, $p=0.737)$.

3.3. The Thiol Form to Disulfide Form Ratio of Cysteine (Cys/CySS) in Plasma. As Figure 1 shows, the Cys/CySS ratio in MT group was significantly greater than in WT and UT groups in all of the recorded times: pre-exs $(F=5.357$, $p=0.011)$, post-exs $(F=5.600, p=0.009)$, post $-10 \mathrm{~min}$ $(F=6.656, p=0.004)$, and post $-30 \mathrm{~min}(F=5.403, p=$ $0.011)$. This ratio was significantly decreased immediately after exercise in all groups ( $p=0.003)$ and after $10 \mathrm{~min}$ it was started to increase till $30 \mathrm{~min}$ after exercise. The decrease in the Cys/CySS ratio was secondary to the decrease in plasma Cys level and increase in CySS levels (Table 4).

3.4. The Redox State of GSH/GSSG in Plasma. Plasma level of GSH in MT group was significantly greater than in WT and UT groups in pre-exs $(F=5.853, p=0.008)$, post-exs $(F=$ 7.230, $p=0.003)$, post-10 $\min (F=6.353, p=0.005)$, and post-30 $\mathrm{min}(F=5.026, p=0.014)$. There was no significant change in plasma concentration of GSH following exercise in neither group (Table 4). Plasma GSH/GSSG showed a sharp significant reduction immediately after exercise $(p<0.001$ in all groups) till the end of $10 \mathrm{~min}$ after exercise (WT: $p=$ 0.001, MT and UT: $p<0.001$ ) and then turned to strong rising till $30 \mathrm{~min}$ after the exercise in all groups (Figure 2). The preexercise value in MT group was significantly greater than in WT and UT groups at basal $(F=6.666, p=0.004)$ and end point $(F=4.536, p=0.020)$ values (Figure 2$)$.

3.5. The Redox State of GSH/GSSG in Red Blood Cell (RBC). Red blood cells GSH level was increased in MT ( $p=0.012)$ and WT ( $p=0.018$ ) groups immediately after exercise and then started to reduce during the further time course of study in MT group. Immediately after exercise level of GSH in RBCs in MT group was significantly greater than in UT group, ( $p=0.022$, Table 4$)$. Inversely, the untrained

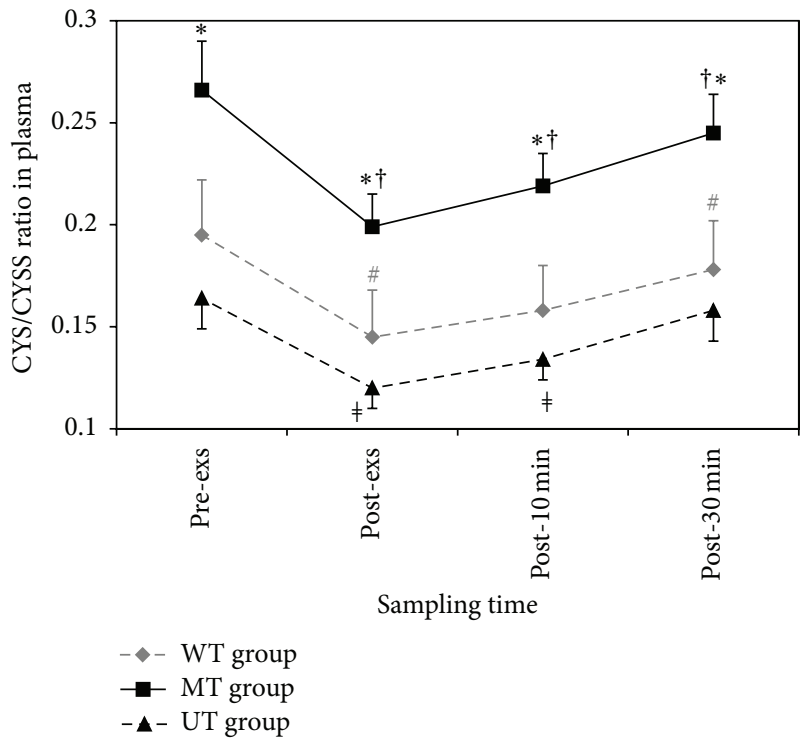

FIGURE 1: Effects of one session of aerobic exercise on plasma Cys/CySS in subjects with different physical training status. Values represent mean \pm SEM $(n=10)$ for each time point. * MT group versus WT and UT groups in pre-exs $(F=5.357, p=0.011)$, postexs $(F=5.600, p=0.009)$, post-10 $\min (F=6.656, p=0.004)$, and post-30 $\min (F=5.403, p=0.011)$; \# WT group by time $(p<0.001)$; $\dagger$ MT group by time $(p=0.001)$; $\neq$ UT group by time $(p<0.001)$.

group showed significant reduction in GSH ( $p=0.002)$. The level of GSSG in RBCs in MT group was lower than in WT group immediately $(p=0.008)$ and $10 \min (p=0.025)$ after exercise. Interestingly, GSSG level in untrained $(p=0.004)$ and well-trained individuals showed a significant increase $(p=0.006)$ immediately after exercise (Table 4$)$.

The changes of GSH/GSSG in RBCs are shown in Figure 3. Immediately after exercise, there was a statistically significant decrease in UT group $(p=0.003)$ and there was a statistically significant increase in MT group $(p=0.007)$, whereas the well-trained subjects did not show any significant 


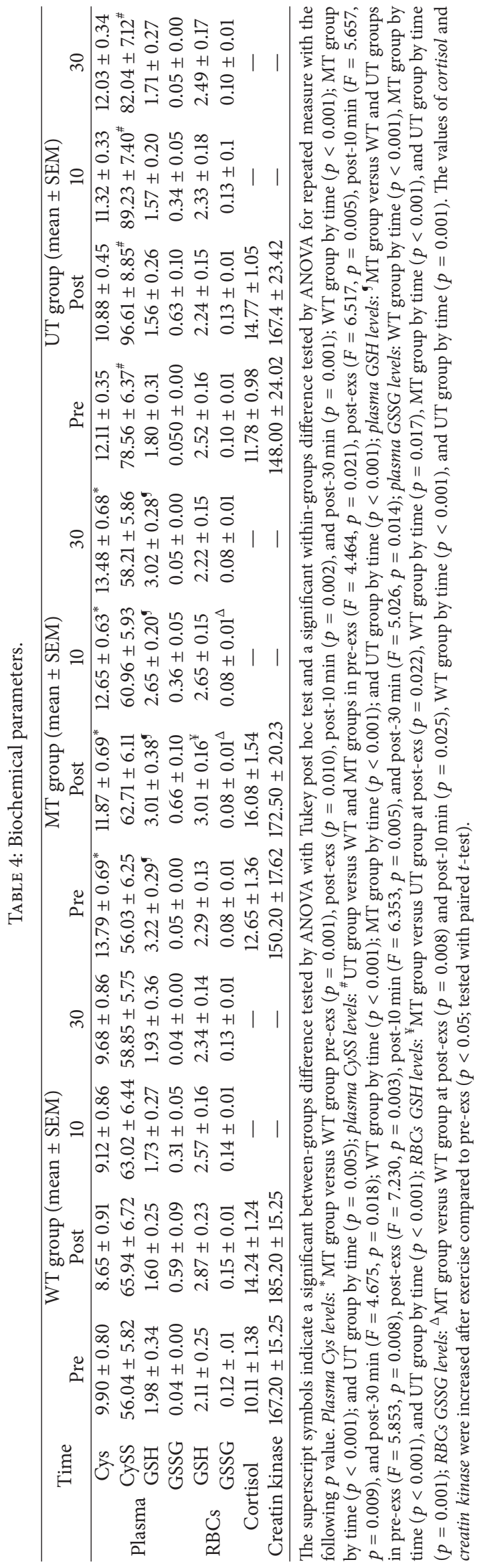



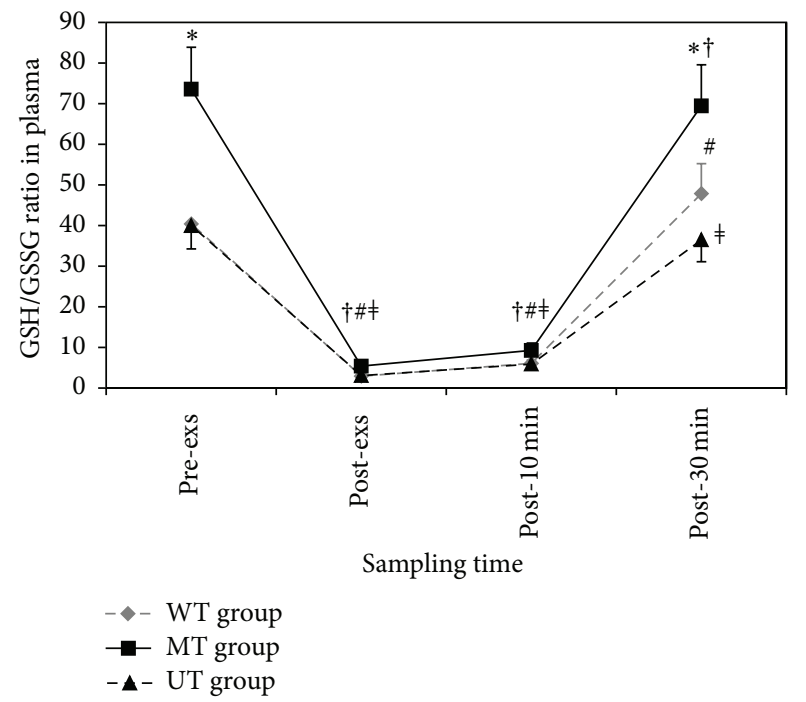

Figure 2: Effects of one session of aerobic exercise on plasma GSH/GSSG in subjects with different physical training status: values represent mean \pm SEM. * MT group versus WT and UT groups in basal $(F=6.666, p=0.004)$ and end point $(F=4.536, p=0.020)$ values. \# $(p<0.001)$ WT group by time; $\dagger(p<0.001)$ MT group by time; $\neq(p<0.001)$ UT group by time.

changes $(p=1.000)$. The ratio of GSH/GSSG in RBCs in MT group was significantly greater than in WT and UT groups for preexercise $(F=4.176, p=0.026)$, post-exs $(F=9.202$, $p=0.001)$, post $10 \mathrm{~min}(F=5.890, p=0.008)$, and post$30 \min (F=3.737, p=0.037)$.

\section{Discussion}

The aim of this study was to evaluate the changes in glutathione redox ratio expressed as GSH/GSSG and Cys/CySS in plasma and also GSH/GSSG in RBCs in subjects with different physical training status. Our results showed that physical training status affected the plasma GSH/GSSG and Cys/CySS ratio and RBCs GSH/GSSG ratio at baseline and after exercise.

All groups experienced one session of physical stress and showed cortisol elevation without significant between-groups differences, excluding the possibility of hypothalamusadrenal axis adaptation in WT group [24].

Also, this finding confirms that exercise with $75 \% \mathrm{Vo}_{2} \max$ can be a physiological stress for all subjects independently of their physical fitness status. This finding is in agreement with other previous studies [25-27].

No significant difference in preexercise values of CK reflects that groups were well matched in terms of previous muscle damage and inflammation. Following exercise, CK showed elevation in all groups with no between-groups differences. Elevation in serum creatine kinase in all groups probably reflects exercise-induced muscle damage in sarcomeres $\mathrm{Z}$ disk [28] or change in permeability of the muscle vasculature $[29,30]$. Our findings are in agreement with studies showing an increase in CK following high intensive aerobic exercise in untrained, moderately trained [31], and well-trained [32] individuals.

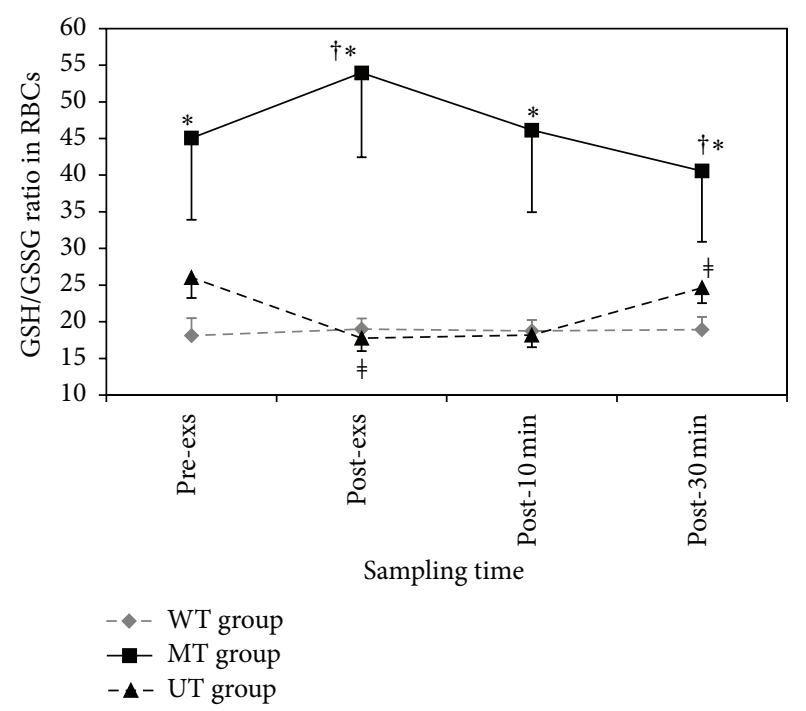

FIGURE 3: Effects of one session of aerobic exercise on GSH/GSSG ratio in red blood cell (RBC) in subjects with different physical training status: values represent mean $\pm \operatorname{SEM}(n=10)$ for each time point. $*(F=4.176, p=0.026)$ MT group versus WT and UT groups in pre- and post-exs $(F=9.202, p=0.001)$, post-10 $\min (F=5.890$, $p=0.008)$, and post-30 $\min (F=3.737, p=0.037)$; $\dagger$ MT group by time $(p<0.001)$; ₹ UT group by time $(p=0.006)$.

Preexercise analysis revealed the highest level of plasma GSH and GSH/GSSG in MT group with moderate $\mathrm{Vo}_{2}$ max $(52.76 \pm 2.62 \mathrm{~mL} / \mathrm{min} / \mathrm{kg})$ and training frequency $(1.20 \pm$ $0.16 \mathrm{~h} /$ week). On the other hand, WT group with more $\mathrm{Vo}_{2} \max (60.90 \pm 3.96 \mathrm{~mL} / \mathrm{min} / \mathrm{kg})$ and also training frequency ( $6.4 \pm 0.33 \mathrm{~h} /$ week) showed the lowest plasma levels of GSH/GSSG. The lowest GSH/GSSG might be related to chronic oxidative stress and poor antioxidant capacity resulting from previous strenuous training in well-trained athletes [33]. The novelty of this study compared to similar investigations [20,34-36] is that here we considered exercise effect on oxidative stress and cellular redox state in three distinct physical training statuses of well-trained, moderately trained, and untrained subjects. To our knowledge, no study considered the effect of physical activity with moderate intensity on redox state, and there are discrepancies in obtained data. For example, Pittaluga et al. in their study reported positive relationship between GSH/GSSG and $\mathrm{Vo}_{2} \max$ in athletes [36], and Michelet et al., similar to what we did, reported the highest GSH/GSSG in individuals with habitual physical training [37].

As mentioned before, glutathione couple GSH/GSSG is a critically important redox biomarker [38] which together with Cys/CySS participates in homeostasis of cellular redox [39]. For example, GSH/GSSG is involved in storage and transport of nitric oxide, reducing ribonucleotides to deoxyribonucleotides, processing of some proteins, interfering in redox signaling pathways, detoxification of xenobiotics [40], and finally protecting cells from oxidative stress [12]. Our data suggest that subjects from MT group with higher GSH/GSSG ratio are predicted to be healthier than those from WT group. Probable reasons could be more antioxidant 
enzymes in MT or more cells damage due to chronic oxidative stress in WT group [41]. However, changes in antioxidant enzymes and oxidative stress markers remain to be elucidated in the future studies.

In addition, plasma analysis revealed a significant reduction in GSH/GSSG and Cys/CySS in all groups, reflecting exercise-induced oxidative stress. Considering the fact that GSH/GSSG and Cys/CySS couples in blood plasma stand for clinical measure of oxidative stress [4], reduction in plasma GSH/GSSG causes a transient shift in redox balance towards a more oxidizing environment. Since consumption of GSH or increase in GSSG production could shift redox balance towards a more oxidizing environment, the decrease in plasma GSH/GSSG might be related to increase in leakage of GSSG from the cells [40-43]. In other words, reduction in plasma GSH/GSSG is secondary to elevation in plasma GSSG levels [44-47]. However, consumption of GSH following intensive acute exercise due to elevation in ROS cannot be excluded too [11]. Similar to our finding, reduction in plasma GSH has been reported by Viguie et al. [44]. In order to ensure redox homeostasis, the secretion of GSH from the liver to the plasma [48] plays a pivotal role.

Regarding the fact that changes in plasma thiols, especially oxidized glutathione and GSH/GSSG ratio, have been used as markers of oxidative stress status in biological systems $[4,10,42]$, significant increase in GSSG and further decrease in the GSH/GSSG immediately after the exercise probably indicate elevation in free-radical production [44, 49]. We should emphasize here that the changes in the GSSG levels and GSH/GSSG ratio were transient and returned to the baseline value $30 \mathrm{~min}$ after the exercise.

Finally, RBCs GSH/GSSG ratio showed no change, elevation, and reduction in WT, MT, and UT groups, respectively. The lowest level of RBC GSH/GSSG and the highest level of GSSG in WT group compared with other groups indicate the lowest reducing power in red blood cells in this group. The possible explanation for this finding might be that chronic production of free radicals may overwhelm the capacity of the antioxidant defense system and leads to a permanent shift in redox balance towards a more oxidizing environment [6] due to a prolonged increase in ROS levels, in accordance with the principle of hormesis [49]. In other words, the cells may enter a state of "chronic oxidative stress" that induces upregulation of the antioxidant potential with enhancement in metabolism and energy consumption to replace consumed GSH and/or transport it to the places where it is needed [12].

In moderately trained subjects, RBCs GSH/GSSG ratio was increased following exercise. This increase was secondary to increase in GSH and decrease in GSSG. The exact physiologic mechanisms of this increase have not been understood yet [50], but activation of MAPK and NF- $\kappa$ B in the inflammation signaling pathways in an effort to restore redox balance could be one reason for elevation of GSH/GSSG. Thus, exercise-induced changes in the glutathione system seem to be effective in RBCs and may prevent ROS-induced cell damage $[20,51]$. Therefore, these participants benefit from sufficient antioxidant power based on hormetic-associated upregulation of antioxidant defense [7, 20, 52].
In untrained young men (UT group), the GSH level and GSH/GSSG ratio in RBCs decreased and GSSG level increased following exercise. Thus, these participants are predicted to suffer from inadequate level of RBCs antioxidant protection system encountering exercise and are predisposed to RBC damage and further related diseases [53].

It is important to notice that selected body fluid is important in detection of redox biomarkers [38]. Glutathione and its disulfide form are found in all extracellular biological fluids, including plasma, interstitial fluid, cerebrospinal fluid, alveolar lining fluid, saliva, bile, pancreatic fluid, tears, sweat, and urine [54]. Here, we chose blood as an extracellular fluid circulating between body cells and exchanging redox biomarkers according to the metabolism and physiological states [38]. In addition, blood plasma and cells are a noticeable generator of reactive species. In fact, blood plasma contains metal ions and oxidized metabolites (glucose, albumin, and fatty acids) which potentially could generate reactive species [55].

It is important to notice that distribution of GSH and GSSG among body fluids and tissues is not equal. For example, in our study, the concentration of GSH in RBCs of UT and WT groups was 1400- and 12300-fold higher than plasma, which confirms the previous report about fluid and tissue GSH relationship $[54,56]$. Finally, considering the finding that the changes in RBC GSH/GSSG are not parallel with plasma GSH/GSSG suggests that plasma redox biomarkers might not accurately reflect tissue redox status compared with RBC biomarkers. As mentioned above, one limitation of the present work is lack of data on cell oxidative stress biomarkers after an acute exercise which is suggested for future studies.

\section{Conclusion}

Our results point to the conclusion that the effect of high intensity acute exercise on glutathione redox ratio depends on physical training status of individuals. Therefore, it seems that a lifestyle with moderate regular exercise training will improve health by shifting in "redox" balance towards more reducing environment, encountering stressful conditions.

\section{Competing Interests}

The authors declare that no competing financial interests exist.

\section{Acknowledgments}

Gratitude is expressed to the subjects who participated in this study.

\section{References}

[1] M. Valko, D. Leibfritz, J. Moncol, M. T. D. Cronin, M. Mazur, and J. Telser, "Free radicals and antioxidants in normal physiological functions and human disease," International Journal of Biochemistry and Cell Biology, vol. 39, no. 1, pp. 44-84, 2007. 
[2] F. Q. Schafer and G. R. Buettner, "Redox environment of the cell as viewed through the redox state of the glutathione disulfide/glutathione couple," Free Radical Biology and Medicine, vol. 30, no. 11, pp. 1191-1212, 2001.

[3] M. Ookhtens and N. Kaplowitz, "Role of the liver in interorgan homeostasis of glutathione and cyst(e)ine," Seminars in Liver Disease, vol. 18, no. 4, pp. 313-329, 1998.

[4] D. P. Jones, "Redefining oxidative stress," Antioxidants and Redox Signaling, vol. 8, no. 9-10, pp. 1865-1879, 2006.

[5] D. P. Jones and Y. Liang, "Measuring the poise of thiol/disulfide couples in vivo," Free Radical Biology and Medicine, vol. 47, no. 10, pp. 1329-1338, 2009.

[6] W. Dröge, "Free radicals in the physiological control of cell function," Physiological Reviews, vol. 82, no. 1, pp. 47-95, 2002.

[7] H. Y. Chung, M. Cesari, S. Anton et al., "Molecular inflammation: underpinnings of aging and age-related diseases," Ageing Research Reviews, vol. 8, no. 1, pp. 18-30, 2009.

[8] D. P. Jones, "Radical-free biology of oxidative stress," American Journal of Physiology-Cell Physiology, vol. 295, no. 4, pp. C849C868, 2008.

[9] M. G. Nikolaidis, A. Kyparos, C. Spanou, V. Paschalis, A. A. Theodorou, and I. S. Vrabas, "Redox biology of exercise: an integrative and comparative consideration of some overlooked issues," Journal of Experimental Biology, vol. 215, no. 10, pp. 16151625, 2012.

[10] D. E. Laaksonen, M. Atalay, L. Niskanen, M. Uusitupa, O. Hänninen, and C. K. Sen, "Blood glutathione homeostasis as a determinant of resting and exercise-induced oxidative stress in young men," Redox Report, vol. 4, no. 1-2, pp. 53-59, 1999.

[11] N. B. J. Vollaard, J. P. Shearman, and C. E. Cooper, "Exerciseinduced oxidative stress: myths, realities and physiological relevance," Sports Medicine, vol. 35, no. 12, pp. 1045-1062, 2005.

[12] V. I. Lushchak, "Adaptive response to oxidative stress: bacteria, fungi, plants and animals," Comparative Biochemistry and Physiology C: Toxicology and Pharmacology, vol. 153, no. 2, pp. 175190, 2011.

[13] V. I. Lushchak, "Glutathione homeostasis and functions: potential targets for medical interventions," Journal of Amino Acids, vol. 2012, Article ID 736837, 26 pages, 2012.

[14] I. Dalle-Donne, R. Rossi, R. Colombo, D. Giustarini, and A. Milzani, "Biomarkers of oxidative damage in human disease," Clinical Chemistry, vol. 52, no. 4, pp. 601-623, 2006.

[15] M. Kemp, Y.-M. Go, and D. P. Jones, "Nonequilibrium thermodynamics of thiol/disulfide redox systems: a perspective on redox systems biology," Free Radical Biology and Medicine, vol. 44, no. 6, pp. 921-937, 2008.

[16] D. Djordjevic, D. Cubrilo, V. Zivkovic, N. Barudzic, M. Vuletic, and V. Jakovljevic, "Pre-exercise superoxide dismutase activity affects the pro/antioxidant response to acute exercise," Serbian Journal of Experimental and Clinical Research, vol. 11, no. 4, pp. 135-139, 2010.

[17] E. C. Gomes, A. N. Silva, and M. R. de Oliveira, "Oxidants, antioxidants, and the beneficial roles of exercise-induced production of reactive species," Oxidative Medicine and Cellular Longevity, vol. 2012, Article ID 756132, 12 pages, 2012.

[18] T. K. Tong, H. Lin, G. Lippi, J. Nie, and Y. Tian, "Serum oxidant and antioxidant status in adolescents undergoing professional endurance sports training," Oxidative Medicine and Cellular Longevity, vol. 2012, Article ID 741239, 7 pages, 2012.

[19] D. P. Jones, “The health dividend of glutathione," Natural Medicine Journal, 2011.
[20] E. Unt, C. Kairane, I. Vaher, and M. Zilmer, "Red blood cell and whole blood glutathione redox status in endurance-trained men following a ski marathon," Journal of Sports Science and Medicine, vol. 7, no. 3, pp. 344-349, 2008.

[21] D. Mahler, V. Froelicher, N. Miller et al., ACSM's Guidelines for Exercise Testing and Prescription, Lippincott Williams \& Wilkins, Philadelphia, Pa, USA, 1995.

[22] D. B. Dill and D. L. Costill, "Calculation of percentage changes in volumes of blood, plasma, and red cells in dehydration," Journal of Applied Physiology, vol. 37, no. 2, pp. 247-248, 1974.

[23] C. Cereser, J. R. M. Guichard, J. Drai et al., "Quantitation of reduced and total glutathione at the femtomole level by high-performance liquid chromatography with fluorescence detection: application to red blood cells and cultured fibroblasts," Journal of Chromatography B: Biomedical Sciences and Applications, vol. 752, no. 1, pp. 123-132, 2001.

[24] G. A. Brooks, T. D. Fahey, T. P. White et al., Exercise Physiology: Human Bioenergetics and Its Applications, Mayfield Publishing Company, Mountain View, Calif, USA, 2000.

[25] A. C. Hackney, "Stress and the neuroendocrine system: the role of exercise as a stressor and modifier of stress," Expert Review of Endocrinology and Metabolism, vol. 1, no. 6, pp. 783-792, 2006.

[26] C. T. M. Davies and J. D. Few, "Effects of exercise on adrenocortical function," Journal of Applied Physiology, vol. 35, no. 6, pp. 887-891, 1973.

[27] E. E. Hill, E. Zacki, C. Battaglini, M. Viru, A. Viru, and A. C. Hackney, "Exercise and circulating cortisol levels: the intensity threshold effect," Journal of Endocrinological Investigation, vol. 31, no. 7, pp. 587-591, 2008.

[28] L. Féasson, D. Stockholm, D. Freyssenet et al., "Molecular adaptations of neuromuscular disease-associated proteins in response to eccentric exercise in human skeletal muscle," The Journal of Physiology, vol. 543, no. 1, pp. 297-306, 2002.

[29] J. G. Cannon, S. F. Orencole, R. A. Fielding et al., "Acute phase response in exercise: interaction of age and vitamin $\mathrm{E}$ on neutrophils and muscle enzyme release," The American Journal of Physiology, vol. 259, no. 6, pp. R1214-R1219, 1990.

[30] R. B. Armstrong, G. L. Warren, and J. A. Warren, "Mechanisms of exercise-induced muscle fibre injury," Sports Medicine, vol.12, no. 3, pp. 184-207, 1991.

[31] F. Seifi-Skishahr, M. Siahkohian, and B. Nakhostin-Roohi, "Influence of aerobic exercise at high and moderate intensities on lipid peroxidation in untrained men," Journal of Sports Medicine and Physical Fitness, vol. 48, no. 4, pp. 515-521, 2008.

[32] S. Chevion, D. S. Moran, Y. Heled et al., "Plasma antioxidant status and cell injury after severe physical exercise," Proceedings of the National Academy of Sciences of the United States of America, vol. 100, no. 9, pp. 5119-5123, 2003.

[33] M. Kretzschmar and D. Muller, "Aging, training and exercise: a review of effects on plasma glutathione and lipid peroxides," Sports Medicine, vol. 15, no. 3, pp. 196-209, 1993.

[34] D. Z. Djordjevic, D. G. Cubrilo, V. S. Puzovic et al., "Changes in athlete's redox state induced by habitual and unaccustomed exercise," Oxidative Medicine and Cellular Longevity, vol. 2012, Article ID 805850, 7 pages, 2012.

[35] F. Marzatico, O. Pansarasa, L. Bertorelli, L. Somenzini, and G. Della Valle, "Blood free radical antioxidant enzymes and lipid peroxides following long-distance and lactacidemic performances in highly trained aerobic and sprint athletes," Journal of Sports Medicine and Physical Fitness, vol. 37, no. 4, pp. 235239, 1997. 
[36] M. Pittaluga, P. Parisi, S. Sabatini et al., "Cellular and biochemical parameters of exercise-induced oxidative stress: relationship with training levels," Free Radical Research, vol. 40, no. 6, pp. 607-614, 2006.

[37] F. Michelet, R. Gueguen, P. Leroy, M. Wellman, A. Nicolas, and G. Siest, "Blood and plasma glutathione measured in healthy subjects by HPLC: relation to sex, aging, biological variables, and life habits," Clinical Chemistry, vol. 41, no. 10, pp. 1509-1517, 1995.

[38] M. G. Nikolaidis, N. V. Margaritelis, V. Paschalis, A. A. Theodorou, A. Kyparos, and I. S. Vrabas, "Common questions and tentative answers on how to assess oxidative stress after antioxidant supplementation and exercise," in Antioxidants in Sport Nutrition, M. Lamprecht, Ed., pp. 221-246, CRC Press, Boca Raton, Fla, USA, 2014.

[39] D. P. Jones, Y. Park, N. Gletsu-Miller et al., "Dietary sulfur amino acid effects on fasting plasma cysteine/cystine redox potential in humans," Nutrition, vol. 27, no. 2, pp. 199-205, 2011.

[40] B. Halliwell and J. M. C. Gutteridge, Free Radicals in Biology and Medicine, Clarendon Press, Oxford, UK, 1989.

[41] M.-C. Gomez-Cabrera, E. Domenech, and J. Viña, "Moderate exercise is an antioxidant: upregulation of antioxidant genes by training," Free Radical Biology and Medicine, vol. 44, no. 2, pp. 126-131, 2008.

[42] L. L. Ji, "Antioxidants and oxidative stress in exercise," Proceedings of the Society for Experimental Biology and Medicine, vol. 222, no. 3, pp. 283-292, 1999.

[43] I. Pócsi, R. A. Prade, and M. J. Penninckx, "Glutathione, altruistic metabolite in fungi," Advances in Microbial Physiology, vol. 49, pp. 1-76, 2004.

[44] C. A. Viguie, B. Frei, M. K. Shigenaga, B. N. Ames, L. Packer, and G. A. Brooks, "Antioxidant status and indexes of oxidative stress during consecutive days of exercise," Journal of Applied Physiology, vol. 75, no. 2, pp. 566-572, 1993.

[45] H. Andersson, A. Karlsen, R. Blomhoff, T. Raastad, and F. Kadi, "Plasma antioxidant responses and oxidative stress following a soccer game in elite female players," Scandinavian Journal of Medicine and Science in Sports, vol. 20, no. 4, pp. 600-608, 2010.

[46] S.-C. Chung, A. H. Goldfarb, A. Z. Jamurtas, S. S. Hegde, and J. Lee, "Effect of exercise during the follicular and luteal phases on indices of oxidative stress in healthy women," Medicine and Science in Sports and Exercise, vol. 31, no. 3, pp. 409-413, 1999.

[47] T. A. Watson, R. Callister, R. D. Taylor, D. W. Sibbritt, L. K. Macdonald-Wicks, and M. L. Garg, "Antioxidant restriction and oxidative stress in short-duration exhaustive exercise," Medicine and Science in Sports and Exercise, vol. 37, no. 1, pp. 63-71, 2005.

[48] J. D. Adams Jr., B. H. Lauterburg, and J. R. Mitchell, "Plasma glutathione and glutathione disulfide in the rat: regulation and response to oxidative stress," Journal of Pharmacology and Experimental Therapeutics, vol. 227, no. 3, pp. 749-754, 1983.

[49] R. R. Cook and E. J. Calabrese, "Hormesis is biology, not religion," Environmental Health Perspectives, vol. 114, no. 12, p. A688, 2006.

[50] L. L. Ji, M.-C. Gomez-Cabrera, and J. Vina, "Exercise and hormesis: activation of cellular antioxidant signaling pathway," Annals of the New York Academy of Sciences, vol. 1067, no. 1, pp. 425-435, 2006.

[51] P. Tauler, A. Aguiló, I. Gimeno, E. Fuentespina, J. A. Tur, and A. Pons, "Influence of vitamin $\mathrm{C}$ diet supplementation on endogenous antioxidant defences during exhaustive exercise," Pflugers Archiv European Journal of Physiology, vol. 446, no. 6, pp. 658-664, 2003.
[52] Z. Radak, H. Y. Chung, E. Koltai, A. W. Taylor, and S. Goto, "Exercise, oxidative stress and hormesis," Ageing Research Reviews, vol. 7, no. 1, pp. 34-42, 2008.

[53] F. W. Booth and S. J. Lees, "Fundamental questions about genes, inactivity, and chronic diseases," Physiological Genomics, vol. 28, no. 2, pp. 146-157, 2007.

[54] S. E. Moriarty-Craige and D. P. Jones, "Extracellular thiols and thiol/disulfide redox in metabolism," Annual Review of Nutrition, vol. 24, pp. 481-509, 2004.

[55] M. G. Nikolaidis and A. Z. Jamurtas, "Blood as a reactive species generator and redox status regulator during exercise," Archives of Biochemistry and Biophysics, vol. 490, no. 2, pp. 77-84, 2009.

[56] N. V. Margaritelis, A. S. Veskoukisa, V. Paschalis et al., "Blood reflects tissue oxidative stress: a systematic review," Biomarkers, vol. 20, no. 2, pp. 97-108, 2015. 

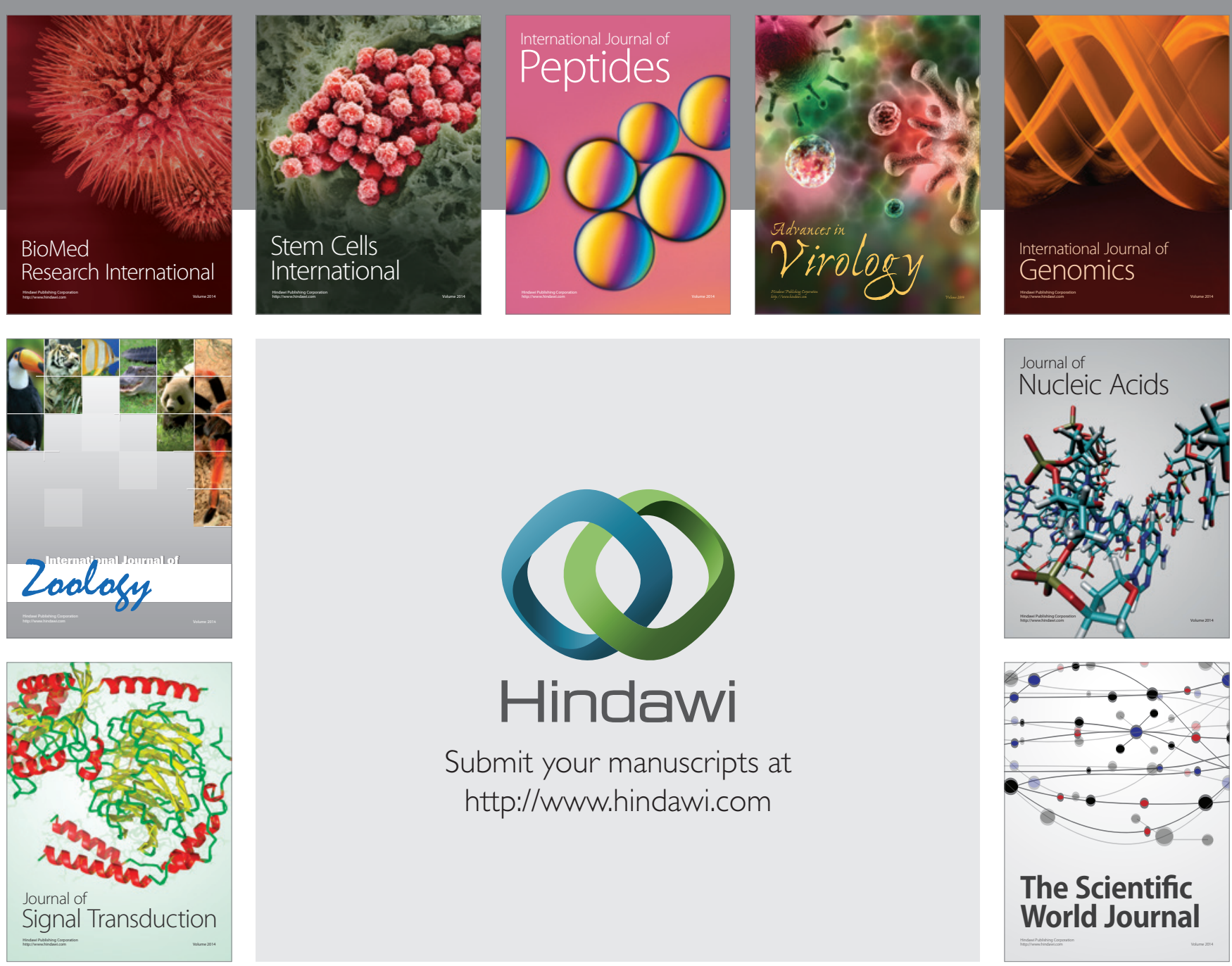

Submit your manuscripts at

http://www.hindawi.com
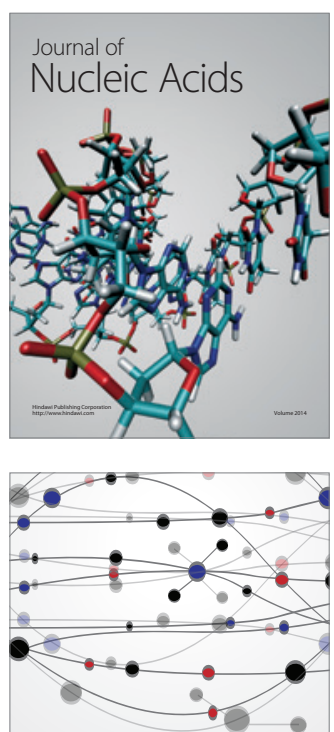

The Scientific World Journal
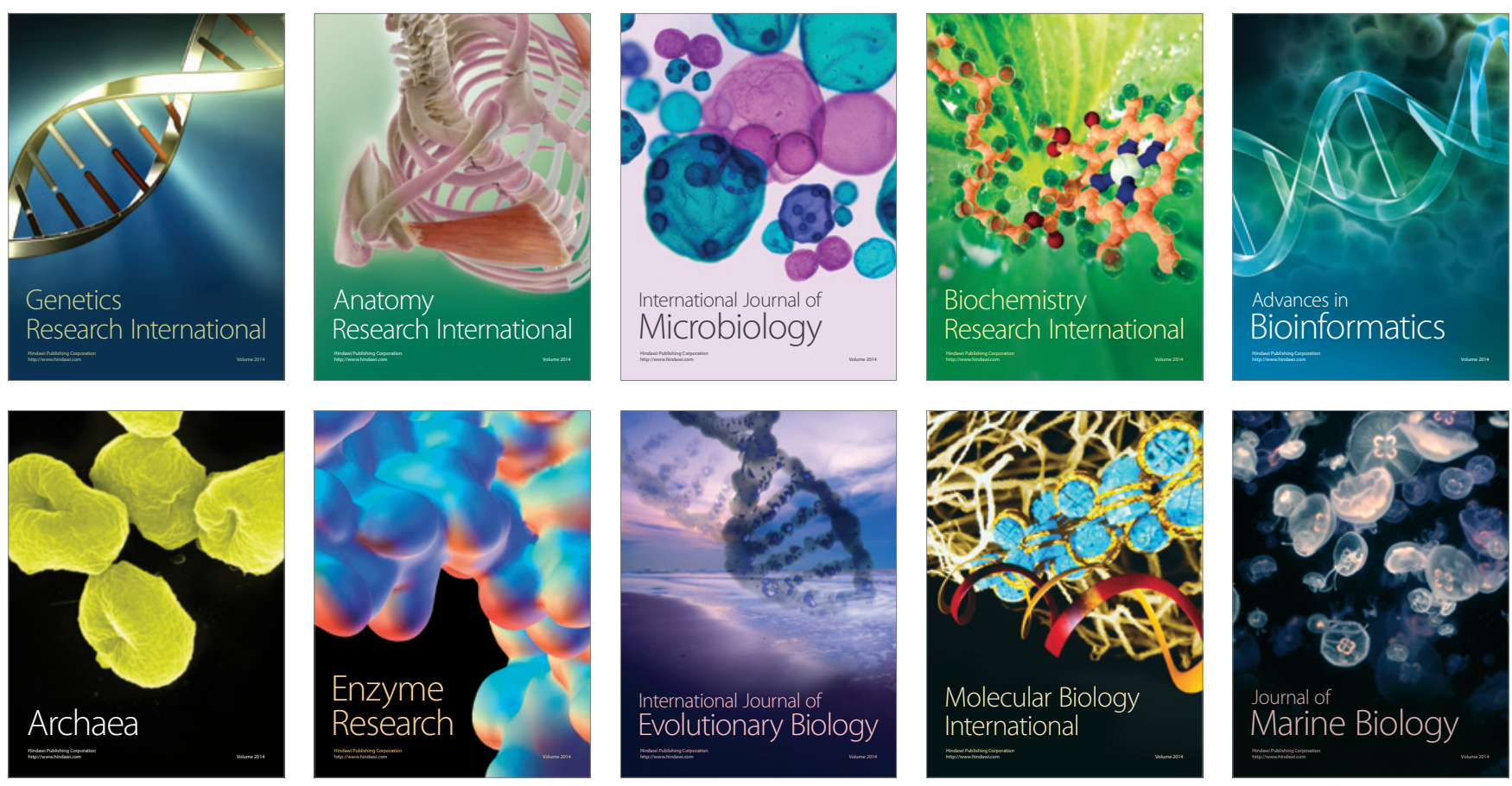